\title{
The causes of new-onset epilepsy and seizures in the elderly
}

\author{
This article was published in the following Dove Press journal: \\ Neuropsychiatric Disease and Treatment \\ 17 June 2016 \\ Number of times this article has been viewed
}

\author{
Shasha Liu' \\ Weihua $\mathrm{Yu}^{2}$ \\ Yang Lü' \\ 'Department of Geriatrics, The First \\ Affiliated Hospital of Chongqing \\ Medical University, ${ }^{2}$ Department of \\ Anatomy, Institute of Neuroscience, \\ Chongqing Medical University, \\ Chongqing, People's Republic of China
}

Correspondence: Yang Lü Department of Geriatrics, The First Affiliated Hospital of Chongqing Medical University, No I Youyi Road, Yuzhong District, Chongqing 4000I6, People's Republic of China

Tel $+86238901 \quad 1622$

Fax +86 $23688|\quad| 487$

Email lyu_yang@126.com

\begin{abstract}
With increasing age, the prevalence and incidence of epilepsy and seizures increases correspondingly. New-onset epilepsy in elderly people often has underlying etiology, including cerebrovascular diseases, primary neuron degenerative disorders, intracerebral tumors, and traumatic head injury. In addition, an acute symptomatic seizure cannot be called epilepsy, which manifests usually as a common symptom secondary to metabolic or toxicity factors in older people. In this review, we have mainly focused on the causes of new-onset epilepsy and seizures in elderly people. This knowledge will certainly help us to understand the reasons for high incidences of epilepsy and seizures in elderly people. We look forward to controlling epileptic seizures via the treatment of primary diseases in the future.
\end{abstract}

Keywords: epilepsy, seizures, causes, elderly

\section{Introduction}

Epilepsy is one of the most common diseases of the nervous system in the elderly, second to dementia and stroke. ${ }^{1}$ Geriatric epilepsy includes pre-elderly ( $<60$ years old) epilepsy continuing to old age stage, and new-onset epilepsy in the elderly. Epilepsy, especially late-onset epilepsy, significantly impacts the quality of life of older people and increases the health care resource burden on society. ${ }^{2}$

Old age stage is a peak period for developing epilepsy and seizures. ${ }^{3}$ The incidence of epilepsy and seizures is higher in the elderly ( $\geq 60$ years old) than in other age groups. ${ }^{4,5}$ It has been estimated that the annual incidence is 85 per 100,000 for people aged 65-69 years, 159 per 100,000 for people aged over 80 years, and 80.8 per 100,000 people over all age groups. ${ }^{6}$ A recent epidemiological study shows that the average annual incidence of epilepsy in the elderly, aged 65 years and older, is up to 240 per $100,000 .{ }^{7}$ Nearly $25 \%$ of new-onset epilepsy occurs in the elderly. ${ }^{8}$ Some scholars predict that the elderly will account for half of all new-onset epilepsy people by $2020 .^{9}$

The existence of some special causes may contribute to the high incidence of epilepsy in the elderly. It is reported that an underlying etiology can be found in nearly $50 \%$ of elderly patients. ${ }^{10}$ In 2010, the International League Against Epilepsy (ILAE) Commission for Classification of Epilepsy divided epilepsies into three categories (genetic, structural/metabolic, unknown cause) according to the etiologies of epilepsy. ${ }^{11}$ This classification applies to all age groups, including the elderly. Specific causes are correlated with the age groups; different age groups tend to have different causes of epilepsy. ${ }^{3}$ Younger patients with epilepsy often show a genetic cause. However, new-onset epilepsy in the elderly is mainly the consequence of accumulated injuries to the brain and other secondary factors. ${ }^{12,13}$ The most common acquired etiologies 
of new-onset epilepsy and seizures in the elderly include cerebrovascular diseases, primary neuron degenerative disorders associated with cognitive impairment, intracerebral tumors, and traumatic head injury., ${ }^{9,14}$ We have summarized the percentage of each cause of new-onset epilepsy in the elderly in Table S1. Identification of the causes in the elderly with new-onset epilepsy or seizures may contribute to seizure control via the treatment of primary diseases.

In this review, we have focused on analyzing the causes of new-onset epilepsy in elderly people. In addition, we have also mentioned potential unknown causes and causes of acute symptomatic seizures. In the last part of our review, we have summarized the common causes of status epilepticus (SE), which is not uncommon in the elderly.

\section{Acquired causes of new-onset epilepsy in the elderly \\ Cerebrovascular diseases}

Stroke and other cerebrovascular diseases are the most important risk factors for new-onset epilepsy in the elderly, which account for $30 \%-50 \%$ in all identified causes. ${ }^{10,15-17}$ In general, epilepsy can occur at the time or after stroke, or can be an early clinical manifestation of cerebrovascular diseases. Studies have reported that the risk of developing epilepsy in the first year after a stroke increases by 20 times. ${ }^{15}$ Table 1 shows the studies in which the risk of developing epilepsy within the first year has been described regarding cerebrovascular diseases. ${ }^{18-24}$ The number of lesions, and the size of the stroke site are closely linked to the probability of the occurrence of epilepsy. A 12-year follow-up study shows that visual neglect, dysphasia, and stroke subtype (particularly total anterior circulation infarcts), are predictors of poststroke epilepsy. ${ }^{25}$ Epilepsy is mainly due to mechanical stimulation of a stroke lesion, nerve cell degeneration, gliosis around the lesion, and glial scar formation. Ischemic stroke, intracerebral hemorrhage, and subarachnoid hemorrhage are common risk factors of poststroke epilepsy. ${ }^{26,27}$

Table I Studies in which the risk of developing epilepsy within the first year has been described regarding cerebrovascular diseases

\begin{tabular}{|c|c|}
\hline Studies & $\begin{array}{l}\text { Patients with poststroke } \\
\text { epilepsy at I year }\end{array}$ \\
\hline Bladin et $\mathrm{al}^{18}$ & $3.8 \%$ ( 9 months) \\
\hline Burn et al ${ }^{19}$ & $4.2 \%$ \\
\hline So et $\mathrm{al}^{20}$ & $3.0 \%$ \\
\hline Lamy et $\mathrm{al}^{21}$ & $3.1 \%$ \\
\hline Lossius et $\mathrm{al}^{22}$ & $2.5 \%$ \\
\hline Roivainen et $\mathrm{a}^{23}$ & $6.9 \%$ \\
\hline Hsu et $\mathrm{a}^{24}$ & $15 \%$ \\
\hline
\end{tabular}

\section{Ischemic stroke}

Several studies have reported that seizures often originate from regions that are only partly destroyed, not from completely infarcted areas. ${ }^{28-30}$ Hemorrhagic transformation of ischemic stroke is a risk factor for epilepsy, ${ }^{31}$ which might be related to the blood-brain barrier disruption. ${ }^{32}$

Thrombotic stroke is common in the elderly because of the coexistence of cardiovascular diseases. One study has shown that patients with suspected cardio embolic etiology have almost two times the risk of developing epilepsy compared with those who have vessel thrombosis, because the thrombosis from the heart is more likely to lead the thrombotic stroke. ${ }^{27}$

Genetic factors account for $30 \%$ of the causes in patients with epilepsy. ${ }^{33}$ In patients with ischemic stroke, genetic factors also contribute to the consequent epileptogenesis. Allele A of the rs671 polymorphism in a gene encoding mitochondrial aldehyde dehydrogenase 2 is associated with poststroke epilepsy. ${ }^{34}$ A CD40-1C/T polymorphism is associated with poststroke epilepsy susceptibility. ${ }^{35}$ Other genes like 12SNPs and a functional connectivity of many genes at the transcriptomics level have been found to exist in the context of ischaemic stroke. Further research is required to determine whether these genes exist in patients with poststroke epilepsy. ${ }^{36}$

In addition, lifestyle factors (eg, smoking, alcohol use), acute metabolic disturbances (eg, acid-base imbalance, electrolyte imbalance, hyperglycemia), non-central nervous system (CNS) morbidities (eg, diabetes 1 or 2, dyslipidemia, renal insufficiency, hypertension, coronary heart diseases or myocardial infarction, peripheral infections), CNS morbidities (eg, early seizures, SE within 2 weeks poststroke, depression or use of antidepressants, dementia), and pharmacotherapy (eg, antiepileptic drugs, noradrenergic blockers, noradrenergic agonists, benzodiazepines, voltage-sensitive calcium-channel blockers, statins) are associated with poststroke epileptogenesis in patients with ischemic stroke. ${ }^{36}$

\section{Hemorrhagic stroke}

Patients with hemorrhagic stroke, especially lesions involving the cerebral cortex, ${ }^{27}$ are more susceptible to develop epilepsy after stroke. Furthermore, lesions with venous injury are more likely to present as epilepsy because venous injury may influence the cortex, for example, intracranial bleeding accompanies cerebral venous thrombosis and shows tendency to secondary epilepsy compared to basal ganglia hemorrhage. ${ }^{27}$ Moreover, subarachnoid hemorrhage is more 
likely to cause epilepsies than intracranial hemorrhage, which is related to secondary bleeding. ${ }^{27}$

\section{Small vessel and microvascular diseases}

Besides large vessel diseases, small vessel and microvascular diseases of the CNS are causes of epilepsy. It is reported that risk factors of cerebrovascular diseases, such as high blood pressure, high cholesterol, and coronary and peripheral arterial disease, are associated with epilepsy, even in the absence of stroke, which is confirmed by radiographic evidence. ${ }^{9}$ Therefore, it is reasonable to suspect that microvascular diseases contribute to geriatric epilepsy. Microvascular diseases such as leukoaraiosis and lacunar infarcts, especially when accompanied with impaired cognition, have a greater risk for poststroke epilepsy than patients without cognitive impairment. ${ }^{37}$ Cerebral amyloid angiopathy is associated with small vessel diseases, including white matter hyperintensities and cerebral microbleeds; some publications report that epilepsy is primarily related to the presence of lobar hemorrhages, which result from cerebral amyloid angiopathy in the elderly. ${ }^{38}$

\section{Other cerebrovascular diseases}

In addition to these common cerebrovascular diseases, other cerebrovascular diseases including cerebral vein and sinus thromboses, or vascular malformations are risk factors for epilepsy. ${ }^{39}$ For patients accompanied by cerebral vein thrombosis, blood deposits in the capillary and venous systems, thereby enabling local brain tissue swelling, nerve cell degeneration, necrosis, and even venous infarction or hemorrhage, eventually leading to the occurrence of epilepsy. Vascular malformations and cavernomas can cause epilepsy, but these are not common in the elderly or in younger patients without bleeding.

\section{Epilepsy and subsequent development of cerebrovascular diseases}

In fact, there is a mutual link between epilepsy and cerebral vascular diseases. In some patients with generalized seizures, mean arterial pressure increases rapidly, leading to aneurysm rupture, and rebleeding, causing seizures. ${ }^{25}$ Cleary et al have shown that the onset of seizures in later life is associated with a striking increase in the risk of stroke, with a threefold risk of subsequent stroke. ${ }^{40}$ Patients presenting with late-onset epilepsy have a greater presence of myocardial infarction, peripheral artery disease, hypertension/left ventricle hypertrophy, high cholesterol level, silent ischemic lesion, and leukoaraiosis. ${ }^{41}$ These factors may increase the incidence of subsequent development of cerebrovascular diseases. Therefore, elderly patients with new-onset epilepsy should be assessed for the risk factors of cerebrovascular diseases, and be given interventions for these risk factors in order to prevent the occurrence of cerebrovascular diseases.

Hepatic enzyme-inducing antiepileptic drugs increase serum lipid levels and other atherogenic markers via the induction of cytochrome P450 and may therefore increase the risk of vascular events. A population-based cohort study conducted by Renoux et al revealed that there is a slight increase in the risk of myocardial infarction with prolonged use of enzyme inducers antiepileptic drugs ( $>24$ months), but not a clear increased risk of stroke. ${ }^{42}$ Therefore, further studies should be conducted to confirm whether antiepileptic drugs increase the risk of stroke.

\section{Primary neurodegenerative disorder associated with cognitive impairment}

Alzheimer's disease (AD) and other neurodegenerative conditions are risk factors of epilepsy. ${ }^{43-45}$ It is reported that patients with all types of dementias are at a fivefold to tenfold increased risk of epilepsy compared to an age-matched population without dementia. ${ }^{46}$ Primary neurodegenerative disorders account for $\sim 10 \%-20 \%$ of all identified causes in older people. ${ }^{47}$ However, the incidence and prevalence of epilepsy in patients with degenerative dementias might be underestimated due to several factors. Firstly, it is difficult to collect the clinical history from caregivers of dementia. Secondly, it is sometimes difficult to recognize the manifestations of seizures in dementia patients because of the many abnormal behaviors that demented patients often manifest.

During primary neurodegenerative disorders, several factors contribute to epilepsy, including the type of neurodegenerative disorder, the severity and process of dementia, epileptiform discharges in patients with dementia, and race.

First, AD is responsible for the largest proportion of dementia patients with epilepsy. The risk of developing seizures and epilepsy for patients with AD is 3-87 times higher than the same-aged general population. ${ }^{48}$ Non-AD dementias increase the risk of partial seizures elevenfold and the risk of generalized seizures sevenfold. ${ }^{49}$ Of all non-AD dementias, Creutzfeldt-Jakob disease has a higher risk to present epilepsy, the incidence of which is up to $20 \%{ }^{50}$ However, mixed dementia, vascular dementia, and dementia with Lewy body may account for a very small percentage of epilepsy. ${ }^{15}$ Unfortunately, there are no data regarding the prevalence of epileptic disorders in vascular dementia, 
Table 2 Different dementias related to epilepsy

\begin{tabular}{ll}
\hline AD & $\begin{array}{l}3-87 \text { times higher than the same-age } \\
\text { general population } \\
\text { Increase the risk of partial } \\
\text { Non-AD dementias }\end{array}$ \\
& $\begin{array}{l}\text { seizures elevenfold and the risk of } \\
\text { generalized seizures sevenfold } \\
\text { The incidence is up to } 20 \%\end{array}$ \\
\hline
\end{tabular}

Note: There are no specific data about other dementias.

Abbreviation: AD, Alzheimer's disease.

mixed dementia, Lewy body disease, and frontotemporal dementia. Table 2 explains the risk of different dementias in relation to epilepsy.

Second, the severity and process of dementia are related to the possibility of developing epilepsy. The severity of this disease may increase the incidence of seizures. ${ }^{51}$ Seizures can occur in $1.5 \%-16 \%$ of patients with mild dementia, compared to $9 \%-64 \%$ of patients with severe dementia. ${ }^{48}$ Secondary epilepsy can occur at any stage of neurodegenerative diseases, but it commonly develops after years of this progressive disorder. ${ }^{52}$ The average time of suffering from epilepsy after the onset of dementia is 6.8 years. ${ }^{53,54}$ The risk of epilepsy increased by $11 \%$ and $26 \%$ at 10 and 15 years, respectively, in a follow-up study of AD patients. ${ }^{55}$ This may be associated with increasing age and increasing severity of the neurodegenerative process.

Third, an epileptiform discharge on electroencephalogram is strongly predictive of seizures in AD patients. ${ }^{56}$ Therefore, the examination of electroencephalogram can be used as an important predictor of seizures for patients with AD.

Fourth, race is possibly related to the incidence of epilepsy in patients with dementia. Limited research has shown that African-American ethnicity is a risk factor for developing seizures in $\mathrm{AD} ;{ }^{56}$ however, this result may be related to the small sample size in the paper. Sherzai et $\mathrm{al}^{44}$ and Scarmeas et $\mathrm{a}^{52}$ did not find this distinction in their studies. Therefore, evidence as to whether race contributes to epilepsy in patients with dementia is inconsistent. Large-scale clinical trials are needed to confirm this relationship.

Specific epileptogenic mechanism is still uncertain in patients with neurodegeneration; there are several reasons that might be associated with secondary epilepsy in dementia, including $\beta$-amyloid deposition, neuronal loss and gliosis, chemical changes, antidementia drugs, and comorbidities. ${ }^{46,48,57-60} \beta$-Amyloid deposition is a pivotal pathologic change in $\mathrm{AD}$, which is also an important epileptogenic mechanism for patients with AD. $\beta$-Amyloid is related to synaptic activity and serves as a potent regulator of synaptic transmission, causing presynaptic facilitation at relatively low concentrations and postsynaptic depression at higher levels, thereby producing epileptiform activity. ${ }^{61}$ This fact is confirmed in an animal experiment on transgenic mice models of AD that showed that high levels of $\beta$-amyloid can induce epileptiform activity and seizures. ${ }^{57}$ The possible selective loss of the inhibitory neurons might be another mechanism of epileptic seizures in $\mathrm{AD}$ patients. ${ }^{54}$ Moreover, chemical changes in $\mathrm{AD}$ patients may induce seizures; these chemical factors include alterations in acetylcholine, dopamine, gamma-aminobutyric acid and other neurotransmitters, or changes in cellular excitotoxicity and sodium and calcium channel functions. ${ }^{53}$ In addition, dementia-associated drug use is an important risk factor for developing epilepsy. Studies have shown that a history of antipsychotic use is a risk factor for new-onset epilepsy in AD. ${ }^{58}$ Evidence regarding whether antidementia drugs can provoke seizures is limited. It has been shown in an animal study that memantine has proconvulsive and anticonvulsive properties. ${ }^{62}$ In a case report, Donepezil was found to provoke seizures. ${ }^{63}$ However, large observational studies are lacking.

Lastly, dementia-associated comorbidities are also risk factors for developing epilepsy. It is reported that hypertension and diabetes may be potential factors for developing epilepsy in $\mathrm{AD} .^{59,60}$

\section{Trauma}

Head trauma is a common cause of intractable epilepsy, accounting for $10 \%-20 \%$ of symptomatic epilepsy in the general population and 5\% of all epilepsy. ${ }^{64}$ One study in children and young adults has shown that the risk of posttraumatic epilepsy is the highest in the first year, although it remains a high risk in the next 10 years or longer. ${ }^{65}$ This phenomenon may also be seen in the elderly. Traumatic brain injury has been proved as a cause of epilepsy in animal models; in fluid-percussion and controlled cortical impact models, spontaneous electrographic seizures have been recorded. ${ }^{64}$ Unfortunately, molecular and cellular changes of predicting epileptogenesis are still unclear.

Older people are more likely to fall, which may result in serious consequences such as head injury; therefore, the risk of post-traumatic epilepsy in people aged 65 years or older becomes higher. Risk factors associated with post-traumatic epilepsy include penetrating injuries, injury severity, biparietal or multiple contusions, intracranial hemorrhage, frontal or temporal location of the lesion, skull fracture, subdural hematoma, brain midline shift greater than $5 \mathrm{~mm}$, amnesia for more than 1 day, loss of consciousness for more than 1 day, prolonged length of post-traumatic amnesia, multiple intracranial procedures, and the occurrence of early 
post-traumatic seizures. ${ }^{64,66,67}$ In addition, one prospective study has found that ApoE4 allele is related to the risk of late post-traumatic epilepsy. ${ }^{68}$

\section{Tumors}

Brain tumor is a common cause of epilepsy second only to cerebrovascular disease in the elderly, accounting for nearly $10 \%-30 \%$ in all causes of geriatric epilepsy. ${ }^{16,69}$ Epilepsy is a common manifestation in patients with brain tumors. Seizures are the onset symptom in $20 \%-40 \%$ of patients with brain tumor; $20 \%-45 \%$ of patients will present with epileptic seizures during the course of the disease. ${ }^{70}$ Epileptic seizures caused by brain tumors may have the serious consequence of increasing mortality in the elderly. ${ }^{69}$

In the elderly, both primary tumors and brain metastases contribute to epilepsy. Common primary tumors associated with epilepsy include primary CNS lymphoma, meningioma, anaplastic ependymoma, and anaplastic astrocytoma. ${ }^{69}$ Brain metastases often originate in the lungs, bladder, pancreas, esophagus, liver, breast, uterus, and colon. ${ }^{69}$ Gliomas, meningiomas, and brain metastases are the most common brain tumors leading to seizures. ${ }^{71}$ Individuals with primary tumors are more prone to develop seizures than those with secondary tumors. Patients with poorly differentiated tumors are more likely to develop seizures compared with those with welldifferentiated tumors. Patients with low-grade tumors such as astrocytoma, oligodendroglioma, and mixed astrocytome I and II have a higher risk of developing epilepsy. ${ }^{70}$

The localization of tumors is also a common factor for developing epilepsy, rating after the types of tumors. Generally, tumors located in the temporal lobes, frontal lobes, and parietal lobes are more likely to cause seizures and epilepsy compared to tumors located in the medullary. ${ }^{27}$

\section{Potential unknown causes of new-onset epilepsy in the elderly}

Although some of new-onset epilepsies in the elderly show identified etiology, one-third to one-half of geriatric epilepsies still have undetected causes, to date, despite the current advances in technology. ${ }^{10}$

Paraneoplastic limbic encephalitis and posterior reversible leukoencephalopathy syndrome are probably the most rare of the unknown causes of new-onset epilepsy in the elderly. Therefore, these rare factors should be taken into account when no identified causes can explain the reason for geriatric epilepsy.

Immune factors may be potential causes in patients with undetected causes. A recent study conducted in the
US of adult patients (most of whom could be considered elderly) in several intensive care units, highlights the immune origin of the novo new-onset refractory SE. In this case, immunomodulatory treatment is more effective than antiepileptic drugs. ${ }^{72}$

\section{Causes of acute symptomatic seizures}

An acute symptomatic seizure is defined as the first seizure attack in people without epilepsy, occurring in close temporal relationship with an acute CNS insult, including metabolic, toxic, structural, infectious, and inflammation; ${ }^{73}$ it differs from provocative seizure which occurs in people with epilepsy. Sleep deprivation, alcohol consumption, and feeling stressed are the most common factors of provocative seizure. ${ }^{74}$

Strictly speaking, acute symptomatic seizures cannot be diagnosed as epilepsy, however, acute symptomatic seizure is a common symptom in older adults, which increases the risk of developing epilepsy. The incidence of acute seizures in patients older than 60 years is $\sim 100$ per 100,000 and increases with each decade of advancing age. ${ }^{75,76}$ Epilepsy persists in one-third of these patients with acute symptomatic seizures. ${ }^{77}$ A study has shown that acute symptomatic seizures are the most common risk factors of SE and/or cluster seizures in the elderly, which is a neurologic emergency; ${ }^{78}$ this phenomenon increases the risk of neurologic emergency for the elderly. Therefore, it is necessary for us to analysis the causes of acute symptomatic seizures in old adults.

Literature has indicated that cerebrovascular diseases, traumatic brain injury, neoplasm, CNS infection, and drug withdrawal are the major causes of acute symptomatic seizure. ${ }^{8}$ We have explained the different etiologies of acute symptomatic seizures in Table 3.

Stroke is the most common cause of acute symptomatic seizures, which account for nearly half of acute symptomatic seizures. ${ }^{79}$ Seizures which are present within 1 week of cerebrovascular disease are attributed to acute symptomatic seizures. Hemorrhage, lobar location, and anterior hemisphere location are related to a higher incidence of early seizures. ${ }^{20,80}$ In the acute phase of stroke, epileptic discharges are induced by ischemia, hypoxia cerebral edema, or direct stimulation of injured neurons. In addition, seizure threshold can be reduced by the merger of dehydration, electrolyte imbalance, or infection in the acute phase. These reactions become pathogenic factors and contribute to acute symptomatic seizures. Within 15 days of a transient ischemic attack or a lacunar infarct, $\sim 1 \%-2 \%$ of patients experience a seizure. ${ }^{81}$ Seizures usually occur within the first 48 hours of ischemic stroke and within hours of subarachnoid hemorrhage. ${ }^{81}$ 
Table 3 Different etiologies of acute symptomatic seizures

Cerebrovascular disease
Traumatic brain injury
Neoplasm
Central nervous system infection
Drugs antibiotics, endocrine drugs, local anesthetics/anti-arrhythmia agents, psychotropic drugs, stimulant drugs, anesthetics, excessive
anticonvulsants
Illicit drugs cocaine, crack, normeperidine, meperidine, methaqualone
Prescription drugs withdrawal barbiturates, benzodiazepines
Internal medicine diseases fever, hypoglycemia, electrolyte imbalance, water intoxication, pneumonia with or without respiratory failure, severe
myxedema, liver failure, renal failure
Lifestyle-associated factors alcohol and alcohol withdrawal

Traumatic brain injury and neoplasm account for nearly $10 \%$ and $9 \%$ of symptomatic seizures, respectively. ${ }^{75}$ Epileptic discharges may be caused by cerebral edema or the irritability of neoplasm. In addition, subdural hematoma and post-traumatic hemorrhage are associated with seizures in patients who have experienced traumatic brain injury. ${ }^{8}$

The elderly, especially people who have underlying diseases with lower immunity, are prone to CNS infections caused by viruses, bacteria, fungi, and parasites. CNS infection is another important risk factor of acute symptomatic seizures, which accounts for nearly $2 \%$ of symptomatic seizures. ${ }^{75} \mathrm{CNS}$ infection, especially affecting the temporal lobe, is a risk factor of SE, and it is more refractory, ${ }^{82}$ so it is one of the causes that we must emphasize in the elderly, with those in developing countries more easily affected by it. As health conditions are poor in developing countries, CNS infection is more common in developing countries than in developed countries. ${ }^{83,84}$

Prescription drug use and drug withdrawal are important risk factors of acute symptomatic seizures in the elderly. Drugs and drug withdrawal account for up to $10 \%$ of acute symptomatic seizures in the elderly. ${ }^{8}$ Common drugs that can cause seizures include antibiotics, endocrine drugs, local anesthetics/anti-arrhythmia agents, psychotropic drugs, stimulant drugs, anesthetics, and excessive anticonvulsants. ${ }^{85,86}$ In addition, drug withdrawal is also sometimes associated with acute symptomatic seizures. For example, the withdrawal of barbiturates and benzodiazepines can lead to acute symptomatic seizures. ${ }^{86}$ Moreover, large doses of medication, parenteral administration, and comorbidity are risk factors of acute symptomatic seizures related to drugs. ${ }^{15}$ The elderly who are long-term hospitalized or have serious illness are more prone to experience drug-related seizures. ${ }^{15}$ In addition, smoking may affect the distribution of theophylline; therefore, smoking patients are particularly prone to have generalized seizures when theophylline is prescribed. ${ }^{15}$

In addition, a number of internal medicine diseases contribute to $10 \%-15 \%$ of acute symptomatic seizures ${ }^{87}$ including fever, hypoglycemia, electrolyte imbalance, water intoxication, pneumonia with or without respiratory failure, severe myxedema, liver failure, and renal failure; however, uremia, liver failure, hypoglycemia, hyponatremia, and hypoxia are the most common internal medicine disease causes. ${ }^{15}$ These metabolic and toxicity factors may reduce seizure threshold, inducing acute symptomatic seizures, with these factors removed, seizures may no longer occur. Electrolyte imbalance, renal failure, and hypoglycemia or hyponatremia, are the most common internal medicine conditions in elderly people in our clinical work.

Electrolyte imbalance is a common factor associated with acute symptomatic seizures in the elderly. Elderly people with poor nutritien, and poor function of the lungs and kidneys are prone to be electrolyte imbalance, thus, it is a risk factor of acute symptomatic seizures, which should not be ignored. The concentration of ions across cell membranes induces abnormal discharge of neurons, thus causing seizures. Seizures may be the only symptom of electrolyte imbalances, which are commonly seen in people with sodium disorders, hypocalcemia $(<5.0 \mathrm{mg} / \mathrm{dL})$, and hypomagnesemia $(<0.8 \mathrm{mg} / \mathrm{dL}){ }^{88,89}$ The more rapid the disturbance develops the more likely it is to induce seizures, ${ }^{90}$ especially when a rapid decrease of serum sodium occurs. ${ }^{91}$ It is recommended that sodium concentration be reduced at a rate below $0.5 \mathrm{mmol} / \mathrm{L} / \mathrm{h}$ to prevent seizures in patients with hypernatremia. ${ }^{92}$

Acute symptomatic seizure is one of the clinical manifestations of uremic encephalopathy, which is currently considered to be associated with a variety of factors, including toxin metabolites, water and salt electrolyte disorders, acid-base balance disorders, and accumulation of dialysis metabolites. Nowadays, dialysis treatments significantly reduce the incidence of uremic encephalopathy.

Hyperglycemia and hypoglycemia are commonly seen in elderly patients, and both can result in seizures. Older people using an inappropriate dose of insulin are prone to 
hyperglycemia or hypoglycemia, resulting in seizures. ${ }^{87}$ Blood glucose is the main energy source of brain cells, abnormal glucose leads to a lack of energy supply with reduced oxygen supply to brain cells, resulting in local or diffuse cerebral ischemia. Patients with non-ketotic hyperosmolar coma have greater possibility of developing seizures than those with diabetic ketoacidosis, which may be due to the anticonvulsant effect of ketosis. ${ }^{93}$

Finally, lifestyle-associated factors, such as alcohol and alcohol withdrawal, also make the elderly more susceptible to a higher risk of acute seizures; although alcohol-associated seizures play a lesser role and such seizures could be selflimiting, they should not be neglected because these seizures often manifest as generalized seizures. ${ }^{84} \mathrm{~A}$ general theory is that alcohol may increase the number of calcium channels and promote seizure activity by augmenting the levels of neurotransmitters. ${ }^{94}$

\section{Status epilepticus}

$\mathrm{SE}$ is a neurological emergency, which is defined as the occurrence of two or more convulsive seizures without full recovery of consciousness between the seizures or continuous convulsive activity lasting for more than 10 minutes. ${ }^{95}$ In clinical work, SE is not uncommon in the elderly. In one retrospective study, SE occurred in $7.5 \%$ patients aged 60 years and older. ${ }^{69}$ Drug use is a factor for SE, being mentioned frequently. It is estimated that $15 \%$ of patients with seizures secondary to drug use can develop SE, especially with the use of antibiotics. ${ }^{96}$

Penicillins, cephalosporins, carbapenems, and quinolones have been reported to result in SE, particularly when used intravenously at high doses in patients with hepatic or renal dysfunction. ${ }^{96}$ Beta-lactam antibiotics and quinolones block gamma-aminobutyric acid and benzodiazepine receptors, and carbapenems and quinolones activate N-methyl-D-aspartateinduced epileptogenesis. ${ }^{96}$ In the cephalosporin group, SE has been reported with the use of ceftriaxone, ceftazidime, cefotaxime, and cefepime. Among the carbapenems, imipenem is more seizurogenic than meropenem. Among quinolones, SE has also been reported with the use of ciprofloxacin, ofloxacin, and gatifloxacin. ${ }^{96}$

In addition, extremes of age, low serum albumin resulting in high free drug level, and coadministration of potentially epileptogenic drugs may also contribute to SE.

It is important to choose an antibiotic with low epileptogenic potential and to use an appropriate dose to prevent seizure, especially in patients with renal impairment. There are no reports on SE associated with the use of aminoglycosides, azithromycin, vancomycin, clindamycin, and teicoplanin, so, these antibiotics may be the best choice for patients with central nervous lesion and renal and liver dysfunction who are prone to seizure. ${ }^{96}$

\section{Acknowledgments}

This study was supported by grants from National Key Clinical Specialties Construction Program of China (No [2013]544), National Key Technology Research and Development Program of the Ministry of Science and Technology of China (2015BAI06B04), Natural Science Foundation Project of Chongqing Science \& Technology Commission (cstc2013jcyjA10013), Scientific and Technological Research Program of Chongqing Municipal Education Commission (KJ120302), and the Project of Chongqing Municipal Health Bureau (2008-2-01). We greatly appreciate Dr Mohan Giri from Chongqing Medical University for helping with the intensive language editing.

\section{Disclosure}

The authors report no conflicts of interest in this work.

\section{References}

1. Brodie MJ, Elder AT, Kwan P. Epilepsy in later life. Lancet Neurol 2009;8:1019-1030.

2. Baker GA, Jacoby A, Buck D, Brooks J, Potts P, Chadwick DW. The quality of life of older people with epilepsy: findings from a UK community study. Seizure. 2001;10:92-99.

3. Hesdorffer DC, Logroscino G, Benn EK, Katri N, Cascino G, Hauser WA Estimating risk for developing epilepsy: a population-based study in Rochester, Minnesota. Neurology. 2011;76:23-27.

4. Olafsson E, Ludvigsson P, Gudmundsson G, Hesdorffer D, Kjartansson O, Hauser WA. Incidence of unprovoked seizures and epilepsy in Iceland and assessment of the epilepsy syndrome classification: a prospective study. Lancet Neurol. 2005;4:627-634.

5. Leppik IE, Birnbaum AK. Epilepsy in the elderly. Ann N Y Acad Sci. 2010;1184:208-224

6. Wallace H, Shorvon S, Tallis R. Age-specific incidence and prevalence rates of treated epilepsy in an unselected population of 2,052,922 and age-specific fertility rates of women with epilepsy. Lancet. 1998;352: 1970-1973.

7. Faught E, Richman J, Martin R, et al. Incidence and prevalence of epilepsy among older US Medicare beneficiaries. Neurology. 2012;78: 448-453.

8. Ghosh S, Jehi LE. New-onset epilepsy in the elderly: challenges for the internist. Cleve Clin J Med. 2014;81:490-498.

9. Pugh MJ, Knoefel JE, Mortensen EM, et al. New-onset epilepsy risk factors in older veterans. J Am Geriatr Soc. 2009;57:237-242.

10. Tanaka A, Akamatsu N, Shouzaki T, et al. Clinical characteristics and treatment responses in new-onset epilepsy in the elderly. Seizure. 2013;22:772-775

11. Berg AT, Berkovic SF, Brodie MJ, et al. Revised terminology and concepts for organization of seizures and epilepsies: report of the ILAE Commission on Classification and Terminology, 2005-2009. Epilepsia. 2010;51:676-685.

12. Spencer D. Seizures and epileptiform activity in early Alzheimer disease: how hard should we be looking. Epilepsy Curr. 2014;14:73-75. 
13. Smith N, Tiwari D. Epilepsy in older people. Rev Clin Gerontol. 2015;25:53-59. doi:10.1017/S0959259815000052.

14. Stephen LJ, Brodie MJ. Epilepsy in elderly people. Lancet. 2000; 355:1441-1446.

15. Assis TMR, Bacellar A, Costa G, Nascimento OJM. Mortality predictors of epilepsy and epileptic seizures among hospitalized elderly. Arq Neuropsiquiatr. 2015;73:510-515.

16. Stefan H, May TW, Pfafflin M, et al. Epilepsy in the elderly: comparing clinical characteristics with younger patients. Acta Neurol Scand. 2014;129:283-293.

17. Sibia RS, Amith Kumar S, Sharma H. Seizure in later life: an ode to the elderly. Int J Res Med Sci. 2014;2:1393-1395.

18. Bladin CF, Alexandrov AV, Bellavance A, et al. Seizures after stroke: a prospective multicenter study. Arch Neurol. 2000;57:1617-1622.

19. Burn J, Dennis M, Bamford J, Sandercock P, Wade D, Warlow C. Epileptic seizures after a first stroke: the Oxfordshire Community Stroke Project. BMJ. 1997;315:1582-1587.

20. So EL, Annegers JF, Hauser WA, O’Brien PC, Whisnant JP. Populationbased study of seizure disorders after cerebral infarction. Neurology. 1996;46:350-355.

21. Lamy C, Domigo V, Semah F, et al. Early and late seizures after cryptogenic ischemic stroke in young adults. Neurology. 2003;60:400-404.

22. Lossius MI, Ronning OM, Slapo GD, Mowinckel P, Gjerstad L. Poststroke epilepsy: occurrence and predictors - a long-term prospective controlled study (Akershus Stroke Study). Epilepsia. 2005;46:1246-1251.

23. Roivainen R, Haapaniemi E, Putaala J, Kaste M, Tatisumak T. Young adult ischaemic stroke related acute symptomatic and late seizures: risk factors. Eur J Neurol. 2013;20:1247-1255.

24. Hsu CJ, Weng WC, Peng SS, Lee WT. Early-onset seizures are correlated with late-onset seizures in children with arterial ischemic stroke. Stroke. 2014;45:1161-1163.

25. Graham NS, Crichton S, Koutroumanidis M, Wolfe CD, Rudd AG. Incidence and associations of poststroke epilepsy: the prospective South London Stroke Register. Stroke. 2013;44:605-611.

26. Szaflarski JP, Rackley AY, Kleindorfer DO, et al. Incidence of seizures in the acute phase of stroke: a population-based study. Epilepsia. 2008; 49:974-981

27. Bleck TP. Seven questions about stroke and epilepsy. Epilepsy Curr. 2012;12:225-228.

28. De Reuck JL. Stroke-related seizures and epilepsy. Neurol Neurochir Pol. 2007;41:144-149.

29. Awada A, Omojola MF, Obeid T. Late epileptic seizures after cerebral infarction. Acta Neurol Scand. 1999;99:265-268.

30. Dachet F, Bagla S, Keren-Aviram G, et al. Predicting novel histopathological microlesions in human epileptic brain through transcriptional clustering. Brain. 2015;138:356-370.

31. Alberti A, Paciaroni M, Caso V, Venti M, Palmerini F, Agnelli G. Early seizures in patients with acute stroke: frequency, predictive factors, and effect on clinical outcome. Vasc Health Risk Manag. 2008;4: 715-720.

32. Renu A, Amaro S, Laredo C, et al. Relevance of blood-brain barrier disruption after endovascular treatment of ischemic stroke: dual-energy computed tomographic study. Stroke. 2015;46:673-679.

33. Noebels J. Pathway-driven discovery of epilepsy genes. Nat Neurosci. 2015;18:344-350.

34. Yang H, Song Z, Yang GP, et al. The ALDH2 rs671 polymorphism affects poststroke epilepsy susceptibility and plasma 4-HNE levels. PLoS One. 2014;9:e109634.

35. Zhang B, Chen M, Yang H, Wu T, Song C, Guo R. Evidence for involvement of the CD40/CD40L system in poststroke epilepsy. Neurosci Lett. 2014;567:6-10.

36. Pitkanen A, Roivainen R, Lukasiuk K. Development of epilepsy after ischaemic stroke. Lancet Neurol. Epub 2015 Nov 13.

37. De Reuck J, De Clerck M, Van Maele G. Vascular cognitive impairment in patients with late-onset seizures after an ischemic stroke. Clin Neurol Neurosurg. 2006;108:632-637.
38. Viswanathan A, Greenberg SM. Cerebral amyloid angiopathy in the elderly. Ann Neurol. 2011;70:871-880.

39. Kramer G. Epilepsy in the elderly: some clinical and pharmacotherapeutic aspects. Epilepsia. 2001;42(Suppl 3):55-59.

40. Cleary P, Shorvon S, Tallis R. Late-onset seizures as a predictor of subsequent stroke. Lancet. 2004;363:1184-1186.

41. Brigo F, Tezzon F, Nardone R. Late-onset seizures and risk of subsequent stroke: a systematic review. Epilepsy Behav. 2014;31:9-12.

42. Renoux C, Dell'Aniello S, Saarela O, Filion KB, Boivin JF. Antiepileptic drugs and the risk of ischaemic stroke and myocardial infarction: a population-based cohort study. BMJ Open. 2015;5:e08365.

43. Imfeld P, Bodmer M, Schuerch M, Jick SS, Meier CR. Seizures in patients with Alzheimer's disease or vascular dementia: a populationbased nested case-control analysis. Epilepsia. 2013;54:700-707.

44. Sherzai D, Losey T, Vega S, Sherzai A. Seizures and dementia in the elderly: Nationwide Inpatient Sample 1999-2008. Epilepsy Behav. 2014; 36:53-56.

45. Hesdorffer DC, Hauser WA, Annegers JF, Kokmen E, Rocca WA. Dementia and adult-onset unprovoked seizures. Neurology. 1996;46: 727-730.

46. Rao SC, Dove G, Cascino GD, Petersen RC. Recurrent seizures in patients with dementia: frequency, seizure types, and treatment outcome. Epilepsy Behav. 2009;14:118-120.

47. Hommet C, Mondon K, Camus V, De Toffol B, Constans T. Epilepsy and dementia in the elderly. Dement Geriatr Cogn Disord. 2008;25: 293-300.

48. Pandis D, Scarmeas N. Seizures in Alzheimer disease: clinical and epidemiological data. Epilepsy Curr. 2012;12:184-187.

49. Hesdorffer DC, Hauser WA, Annegers JF, Kokmen E, Rocca WA. Dementia and adult-onset unprovoked seizures. Neurology. 1996; 46:727-730.

50. Appel S, Chapman J, Cohen OS, Rosenmann H, Nitsan Z, Blatt I. Seizures in E200K familial and sporadic Creutzfeldt-Jakob disease. Acta Neurol Scand. 2015;131:152-157.

51. Mendez M, Lim G. Seizures in elderly patients with dementia: epidemiology and management. Drugs Aging. 2003;20:791-803.

52. Scarmeas N, Honig LS, Choi H, et al. Seizures in Alzheimer disease: who, when, and how common. Arch Neurol. 2009;66:992-997.

53. Mendez M, Lim G. Seizures in elderly patients with dementia: epidemiology and management. Drugs Aging. 2003;20:791-803.

54. Mendez MF, Catanzaro P, Doss RC, Aquello R, Frehy WH 2nd. Seizures in Alzheimer's disease: clinicopathologic study. J Geriatr Psychiatry Neurol. 1994;7:230-233.

55. Hauser WA, Morris ML, Heston LL, Anderson VE. Seizures and myoclonus in patients with Alzheimer's disease. Neurology. 1986;36: $1226-1230$.

56. Amatniek JC, Hauser WA, DelCastillo-Castaneda C, et al. Incidence and predictors of seizures in patients with Alzheimer's disease. Epilepsia. 2006; 47:867-872.

57. Palop JJ, Chin J, Roberson ED, et al. Aberrant excitatory neuronal activity and compensatory remodeling of inhibitory hippocampal circuits in mouse models of Alzheimer's disease. Neuron. 2007;55:697-711.

58. Irizarry $\mathrm{MC}$, Jin $\mathrm{S}, \mathrm{He} \mathrm{F}$, et al. Incidence of new-onset seizures in mild to moderate Alzheimer disease. Arch Neurol. 2012;69:368-372.

59. Bernardi S, Scaldaferri N, Vanacore N, et al. Seizures in Alzheimer's disease: a retrospective study of a cohort of outpatients. Epileptic Disord. 2010;12:16-21.

60. Hamberger MJ, Palmese CA, Scarmeas N, Weintraub D, Choi H, Hirsch LJ. A randomized, double-blind, placebo-controlled trial of donepezil to improve memory in epilepsy. Epilepsia. 2007;48:1283-1291.

61. Roberson ED, Hope OA, Martin RC, Schmidt D. Geriatric epilepsy: research and clinical directions for the future. Epilepsy Behav. 2011;22: 103-111.

62. Mares P, Mikulecka A. Different effects of two N-methyl-D-aspartate receptor antagonists on seizures, spontaneous behavior, and motor performance in immature rats. Epilepsy Behav. 2009;14:32-39. 
63. Babic T, Zurak N. Convulsions induced by donepezil. J Neurol Neurosurg Psychiatry. 1999;66:410.

64. Pitkanen A, Bolkvadze T. Head trauma and epilepsy. In: Noebels JL, Avoli M, Rogawski MA, Olsen RW, Delgado-Escueta AV, editors. Jasper's Basic Mechanisms of the Epilepsies. 4th ed. Bethesda (MD): National Center for Biotechnology Information (US); 2012.

65. Christensen J, Pedersen MG, Pedersen CB, Sidenius P, Olsen J, Vestergaard M. Long-term risk of epilepsy after traumatic brain injury in children and young adults: a population-based cohort study. Lancet. 2009;373:1105-1110.

66. Annegers JF, Hauser WA, Coan SP, Rocca WA. A population-based study of seizures after traumatic brain injuries. N Engl J Med. 1998;338: $20-24$.

67. Messor A, Polonara G, Carle F, Gesuita R, Salvolini U. Predicting posttraumatic epilepsy with MRI: prospective longitudinal morphologic study in adults. Epilepsia. 2005;46:1472-1481.

68. Harden CL. The apolipoprotein E epsilon (epsilon) 4 allele is important for trauma-related epilepsy. Epilepsy Curr. 2004;4:29-30.

69. de Assis TR, Bacellar A, Costa G, et al. Etiological prevalence of epilepsy and epileptic seizures in hospitalized elderly in a Brazilian tertiary center-Salvador - Brazil. Arq Neuropsiquiatr. 2015;73: 83-89.

70. Maschio M. Brain tumor-related epilepsy. Curr Neuropharmacol. 2012;10:124-133.

71. Hiyoshi T, Yagi K. Epilepsy in the elderly. Epilepsia. 2000;41(Suppl 9): $31-35$.

72. Gaspard N, Foreman BP, Alvarez V, et al. New-onset refractory status epilepticus: etiology, clinical features, and outcome. Neurology. 2015; 85:1604-1613.

73. Beghi E, Carpio A, Forsgren L, et al. Recommendation for a definition of acute symptomatic seizure. Epilepsia. 2010;51:671-675.

74. Vongkasamchai N, Lertsinudom S, Topark-Ngarm A, et al. Prevalence of provocative seizures in persons with epilepsy: a longitudinal study at Khon Kaen University Hospital, Thailand. Neurol Res Int. 2015;2015: 659189.

75. Annegers JF, Hauser WA, Lee JR, Rocca WA. Incidence of acute symptomatic seizures in Rochester, Minnesota, 1935-1984. Epilepsia. 1995;36:327-333.

76. Loiseau J, Loiseau P, Duche B, Guyot M, Dartiques JF, Aublet B. A survey of epileptic disorders in southwest France: seizures in elderly patients. Ann Neurol. 1990;27:232-237.

77. Holt-Seitz A, Wirrell EC, Sundaram MB. Seizures in the elderly: etiology and prognosis. Can J Neurol Sci. 1999;26:110-114

78. Sinha S, Satishchandra P, Kalband BR, Thennarasu K. New-onset status epilepticus and cluster seizures in the elderly. J Clin Neurosci. 2013;20:423-428.
79. Tabatabaei SS, Delbari A, Salman-Roghani R, et al. Seizures and epilepsy in elderly patients of an urban area of Iran: clinical manifestation, differential diagnosis, etiology, and epilepsy subtypes. Neurol Sci. 2013;34:1441-1446.

80. Labovitz DL, Hauser WA, Sacco RL. Prevalence and predictors of early seizure and status epilepticus after first stroke. Neurology. 2001;57: 200-206.

81. Giroud M, Gras P, Fayolle H, Andre N, Soichot P, Dumas R. Early seizures after acute stroke: a study of 1,640 cases. Epilepsia. 1994;35: 959-964.

82. Holtkamp M, Othman J, Buchheim K, Meierkord H. Predictors and prognosis of refractory status epilepticus treated in a neurological intensive care unit. J Neurol Neurosurg Psychiatry. 2005;76:534-539.

83. Luhdorf K, Jensen LK, Plesner AM. Etiology of seizures in the elderly. Epilepsia. 1986;27:458-463.

84. Pradhan S, Yadav R. Seizures and epilepsy in central nervous system infections. Neurology Asia. 2004;9:4-9.

85. Tallis RC, Fillit HM, Brocklehurst JC. Brocklehurst's textbook of geriatric medicine and gerontology. 6th ed. Philadelphia: Elsevier Health Sciences, 2003.

86. Franson KL, Hay DP, Neppe V, et al. Drug-induced seizures in the elderly. Causative agents and optimal management. Drugs Aging. 1995; 7:38-48.

87. Waterhouse E, Towne A. Seizures in the elderly: nuances in presentation and treatment. Cleve Clin J Med. 2005;72(Suppl 3):S26-S37.

88. Castilla-Guerra L, del CFM, Lopez-Chozas JM, Fernandez-Bolanos R. Electrolytes disturbances and seizures. Epilepsia. 2006;47:1990-1998.

89. Whang R, Hampton EM, Whang DD. Magnesium homeostasis and clinical disorders of magnesium deficiency. Ann Pharmacother. 1994; 28:220-226.

90. Riggs JE. Neurologic manifestations of electrolyte disturbances. Neurol Clin. 2002;20:227-239.

91. Boggs JG. Seizures in medically complex patients. Epilepsia. 1997; 38(Suppl 4):S55-S59.

92. Kahn A, Blum D, Casimir G, Brachet E. Controlled fall in natremia in hypertonic dehydration: possible avoidance of rehydration seizures. Eur J Pediatr. 1981;135:293-296.

93. Gao X, Wee AS, Nick TG. Effect of keto-acidosis on seizure occurrence in diabetic patients. J Miss State Med Assoc. 2005;46:131-133.

94. N'Gouemo P. Altered voltage-gated calcium channels in rat inferior colliculus neurons contribute to alcohol withdrawal seizures. Eur Neuropsychopharmacol. 2015;25:1342-1352.

95. Seinfeld S, Goodkin HP, Shinnar S. Status epilepticus. Cold Spring Harb Perspect Med. 2016;6(3):1-5.

96. Misra UK, Kalita J, Chandra S, Nair PP. Association of antibiotics with status epilepticus. Neurol Sci. 2013;34:327-331. 


\section{Supplementary material}

Table SI The summary of the percentage of each cause of new-onset epilepsy in the elderly

Cerebrovascular diseases account for 30\%-50\%.

Primary neurodegenerative disorders account for $\sim 10 \%-20 \%$.

Head trauma accounts for $10 \%-20 \%$.

Brain tumors account for nearly $10 \%-30 \%$.

One-third to one-half of geriatric epilepsies still have undetected causes, to date.

\section{Publish your work in this journal}

Neuropsychiatric Disease and Treatment is an international, peerreviewed journal of clinical therapeutics and pharmacology focusing on concise rapid reporting of clinical or pre-clinical studies on a range of neuropsychiatric and neurological disorders. This journal is indexed on PubMed Central, the 'PsycINFO' database and CAS,

and is the official journal of The International Neuropsychiatric Association (INA). The manuscript management system is completely online and includes a very quick and fair peer-review system, which is all easy to use. Visit http://www.dovepress.com/testimonials.php to read real quotes from published authors.

Submit your manuscript here: http://www.dovepress.com/neuropsychiatric-disease-and-treatment-journal 